\title{
TOTAL KNEE ARTHROPLASTY IN THE PATIENT WITH PARKINSON'S DISEASE
}

\author{
KELLY G. VINCE, JOHN N. INSALL, CATHERINE E. BANNERMAN
}

From the Hospital for Special Surgery, New York

\begin{abstract}
We have reviewed nine patients with Parkinson's disease who had 12 primary total knee arthroplasties and one revision. Deformities were corrected by conventional techniques and semi-constrained resurfacing arthroplasties were used. Follow-up ranged from two to eight years (average 4.3 years).

Nine of the 12 primary arthroplasties were rated as excellent by the Hospital for Special Surgery knee score system, and three were rated as good. Contrary to previous reports, we feel that total knee arthroplasty performed on patients with Parkinson's disease, is a highly satisfactory procedure, alleviating knee pain and improving function.
\end{abstract}

Parkinson's disease, a relatively common geriatric problem, produces numerous symptoms; tremor, muscular rigidity and abnormalities of gait, posture and facial expression. Physiotherapy with regular exercise ameliorates the stiffness and generally improves function (Steinberg 1976; Gersten 1982; Andrews 1985), but the unfortunate patient who is doubly afflicted with painful arthritis of the knee and Parkinson's disease, cannot comfortably move the joint and maintain motion. Total knee arthroplasty has been condemned for patients with Parkinson's disease by Oni and MacKenney (1985) on the grounds that it "induced hamstring rigidity and caused knee flexion contracture". They reported three patients, all of whom died within six months of surgery.

We undertook this study to test our impression that total knee arthroplasty can improve function and diminish pain in individuals with both conditions. We suggest that surgery does not necessarily cause debilitating flexion contractures, but that patients must be selected with consideration as to age and severity of disease.

K. G. Vince, MD, FRCS(C), Orthopaedic Surgeon Kerlan-Jobe Orthopedic Clinic, 501 E. Hardy Street, Suite 300, Inglewood, California 90301, USA.

J. N. Insall, MD

Hospital for Special Surgery, 535 E. 70th Street, New York, New York 10021, USA.

C. E. Bannerman, MD, Director of Geriatrics

Bay Shores Senior, Health Center, 601 Torrance Boulevard, Redondo Beach, California 90277, USA.

Correspondence should be sent to Dr K. G. Vince.

(C) 1989 British Editorial Society of Bone and Joint Surgery $0301-620 X / 89 / 1025 \$ 2.00$

J Bone Joint Surg [Br] 1989;71-B:51-4.

\section{METHODS}

A retrospective analysis was conducted of all our patients who had Parkinson's disease at the time of total knee arthroplasty. The patients were examined by one or two of the authors at a minimum of two years after operation.

The Hospital for Special Surgery knee rating score was used (Insall 1984). According to this system, scores of 85 to 100 points are excellent; 70 to 84 , good; 60 to 69 , fair; and less than 60 , poor. Knees which require revision or removal of the prosthesis score zero. Those requiring repeat surgery without removal of the prosthesis are rated according to their performance.

Radiographs at the latest follow-up were compared with those taken during the first year after surgery. Alignment was recorded for each and any subsidence or progressive radiolucencies noted. A previously reported zone system (Insall, Lachiewicz and Burstein 1982) was used to define the location and extent of radiolucent lines.

\section{PATIENTS}

Nine patients with Parkinson's disease had 13 total knee replacements at the Hospital for Special Surgery between September 1976 and May 1984. The average age at surgery was 70 years (range 64 to 75 years). Their average weight was $74 \mathrm{~kg}$ (range 61 to $160 \mathrm{~kg}$ ). Four patients had bilateral replacements and in three of them both procedures were carried out under the same anaesthetic. In the other patient, there was a six-month interval between procedures.

In five patients, the diagnosis of Parkinson's disease was first established during pre-operative evaluation for total knee replacement. In each this was confirmed by a 
consulting neurologist who initiated therapy with carbidopa-levodopa. The other four were already under treatment for Parkinson's disease when they presented for knee replacement. All nine patients had both tremor and cogwheel rigidity.

All patients could walk at the time of surgery. Seven had normal balance and two required a cane because of mild ataxia and knee pain. The severity of the Parkinson's disease prior to arthroplasty was graded according to the five stages described by Hoehn and Yahr (1967). Five patients had Stage I, two Stage II, and two Stage III disease (Table I). All 13 knees were originally osteoarthritic; one patient was referred for revision of a septic semi-constrained knee replacement (Fig. 1a).

\section{OPERATION}

Deformities were corrected by conventional techniques (Insall 1984). Eight knees in five patients required release of the medial collateral ligament from its attachment to the proximal tibia, to correct varus malalignment. The fibular collateral ligament was released from the femur in four valgus knees in three patients. All knees showed fixed flexion before the arthroplasty. Eight knees in six patients had flexion deformity measuring less than $10^{\circ}$; three knees in three patients had deformity measuring from 10 to $20^{\circ}$ and two knees in two patients had more than $20^{\circ}$. Flexion deformities greater than $20^{\circ}$ were corrected by posterior capsular release. Three knees required release of the lateral patellar retinaculum to realign the extensor mechanism.

All patients had condylar-type resurfacing arthroplasties. The posterior stabilised knee prosthesis (Insall et al. 1982; Vince et al. 1987, 1988), used routinely for primary arthroplasty on the knee service since 1979, was implanted into 10 joints in seven patients. A custommade posterior stabilised condylar prosthesis, with a medial wedge on the tibial component and intramedullary rods on both tibial and femoral components, was manufactured for the revision arthroplasty (Bartel et al. 1982; Urs et al. 1988) (Fig. 1b). The other two prostheses used were a Total Condylar I (Insall et al. 1983; Vince et al. 1987) and a Total Condylar II. Methylmethacrylate cement was used in each case and all patellae were resurfaced. The cruciate ligaments were excised routinely.

After operation, bulky dressings were applied in the

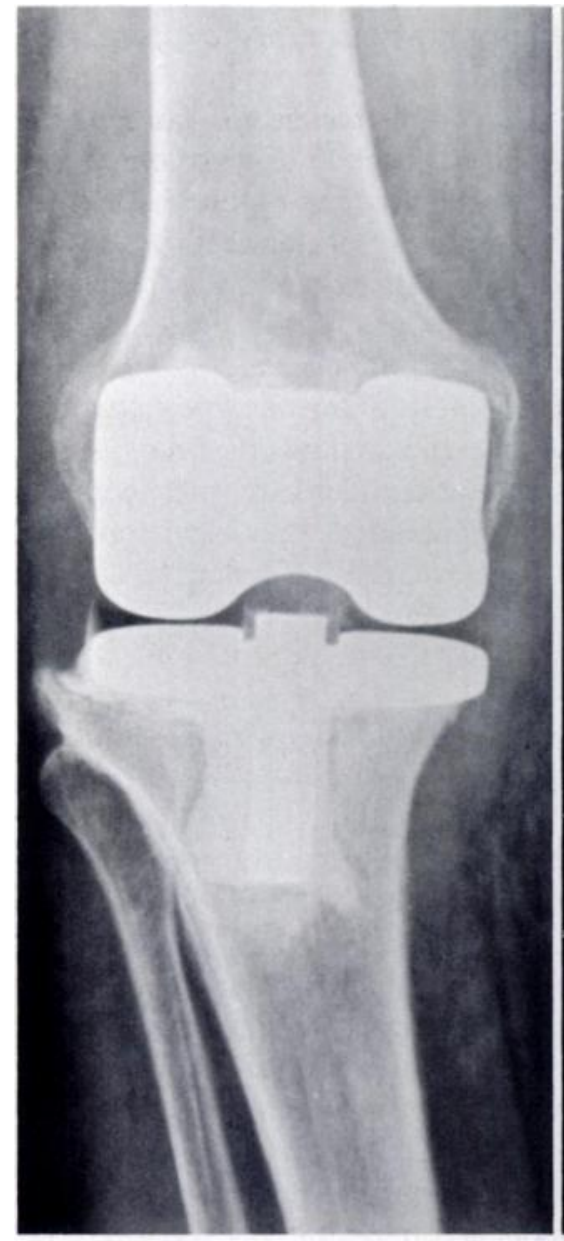

Fig. 1a

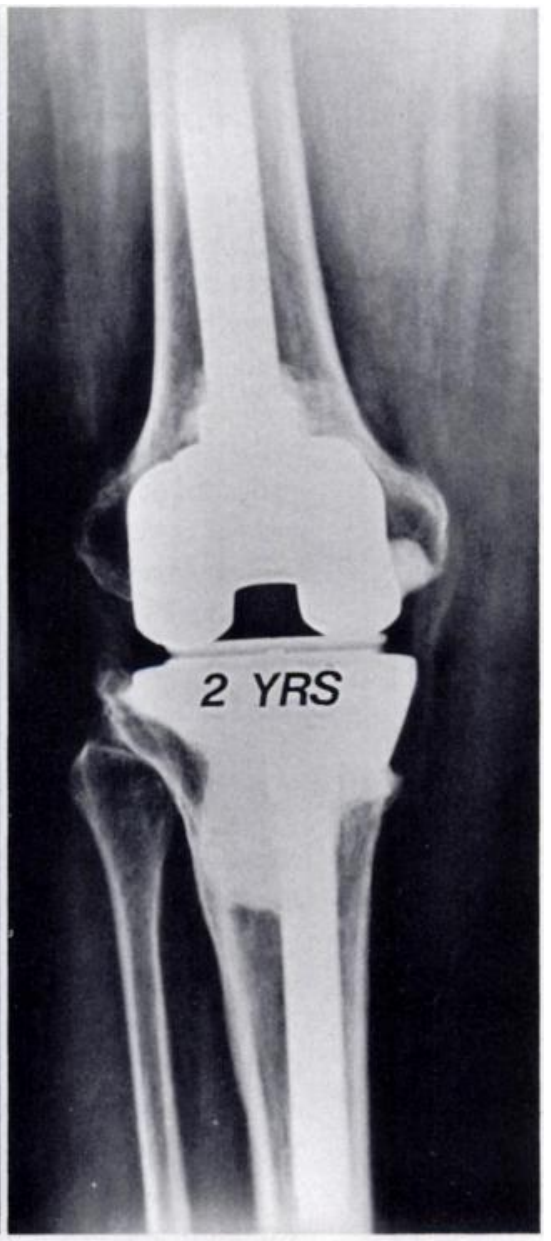

Fig. Ib
Figure 1a - Septic failure of a semi-constrained knee arthroplasty in a 66-year-old patient who had had Parkinson's disease for three years. At the time of revision, she had Stage II disease. The primary arthroplasty was mal-aligned because of a varus cut on the tibia. Figure lb - Revision arthroplasty with a custom-made posterior stabilised prosthesis. The result was "good" at two years. 
operating room and not removed for 14 days (Insall et al. 1982). Consequently, flexion was delayed for two weeks, although walking with crutches or a walker was possible by the fourth postoperative day. Later in the study period, knee movement commenced two days after surgery.

\section{RESULTS}

One patient was assessed at one year; the other eight were evaluated from two to eight years after arthroplasty (average 4.33 years). Nine of 12 primary knee replacements achieved "excellent" scores according to the Hospital for Special Surgery knee rating system by the first postoperative year, and three had "good" scores. There were no fair or poor results.

The mean flexion arc before primary arthroplasty was $97^{\circ}$ (range 48 to $112^{\circ}$ ). Following surgery, the mean flexion was $108^{\circ}$ (range 64 to $120^{\circ}$ ). Two patients had less movement after knee arthroplasty. All flexion deformities were improved by arthroplasty, and 11 knees in seven patients had none, one year after operation. Four knees in three patients developed recurrent flexion deformity of less than $10^{\circ}$ in the first, second and sixth years after surgery, respectively. One patient, who died before the two year follow-up, had a flexion deformity of more than $20^{\circ}$ before operation, and this was reduced to $15^{\circ}$ by knee replacement.

Radiographic assessment. The alignment of 11 knees was corrected to between 3 and $10^{\circ}$ of tibiofemoral valgus, and one was in neutral alignment. Five arthroplasties had radiolucencies in a single zone, none greater than one millimetre. These radiolucencies were present in the initial postoperative radiographs, and in no patient did they progress in width or length. No knee had a radiolucency in more than one zone.

Complications. One patient, with bilateral knee replacements, suffered a small area of skin necrosis which eventually healed and did not require re-operation. Two patients suffered temporary disorientation after surgery.

Table I. Degree of disability from Parkinson's disease (Hoehn and Yahr 1967)

\footnotetext{
Stage

I Unilateral involvement only, usually with minimal or no functional impairment

II Bilateral or midline involvement, without impairment of balance

III First sign of impaired righting reflexes. The patient is unsteady on turning or when pushed from a standing position with the feet together and eyes closed. Function is somewhat restricted but some work may be possible. Patients can lead independent lives with mild to moderate disability

IV Fully developed, severely disabling disease. The patient is able to

walk and stand unassisted but is markedly incapacitated V Confinement to bed or wheelchair, unless aided
}

One intestinal ileus, treated with nasogastric suction, resolved completely. Three patients had postoperative urinary tract infections. There was no joint sepsis and no pneumonia.

Venograms were performed on all patients after surgery. Four patients had positive venograms indicating thrombus in the deep veins of the calf and were treated with warfarin sodium. There was one symptomatic pulmonary embolus, confirmed by lung scan; it was treated with heparin. Another patient had an asymptomatic pulmonary embolus diagnosed on routine postoperative lung scan. Both patients recovered fully.

One patient, a clergyman, suffered bilateral patellar fractures that healed without additional surgery. Another patient later had a lateral patellar retinacular release to treat painful patellar subluxation. His symptoms were improved but not eliminated.

\section{DISCUSSION}

Parkinson's disease is common in the geriatric population (Lapovsky and Slade 1981) with an incidence of between 18.5 and 20.5 per 100,000 in the United States (Nobrega et al. 1967; Kurland 1958; Rajput 1984). The mean age at onset of primary Parkinson's disease is about 55 years (Hoehn and Yahr 1967); this concentrates the problem in an age group similar to that requiring total knee replacement.

Oni and MacKenney (1985) concluded that Parkinson's disease was responsible for failure of total knee arthroplasty in all three patients they reported. We feel this conclusion bears closer inspection. Each patient in their study was older than the mean age of patients reported here and certainly older than the mean age for other series reporting satisfactory results for knee arthroplasty (Insall et al. 1982, 1983). We know that the complication rate and general outcome of surgery can be expected to vary directly with advancing age irrespective of Parkinson's disease. Other diseases (disseminated breast carcinoma and uraemia) contributed to two of three fatalities in the study by Oni and MacKenney.

While Parkinson's disease is associated with a 1.6 to 3 times greater mortality rate than that in the general population (Hoehn and Yahr 1967; Rajput 1984) there is a wide range in the age at death and in the duration of illness before death (Hoehn and Yahr 1967). A small group of patients will show very slow evolution of disease, retaining balance and reflexes, without severe disability for 20 years or more. Furthermore, current medication alters the prognosis of the disease and controls symptoms (Diamond and Markham 1976; Marttilla et al. 1977; Selby 1984). The three patients reported by Oni and MacKenney are not necessarily typical of Parkinson's disease.

Oni and MacKenney reported avulsion of the quadriceps tendon in one of their patients. No patient in the nine we are reporting suffered this complication, and 
it has occurred only once in two other series reported by us, (Insall et al. 1982, 1983) and then only after a manipulation. We doubt if muscle contracture alone could cause this complication, considering that vigorous patients apply forces several times their body weight through the extensor mechanism when climbing stairs. The tendon may, however, be damaged during surgery, a complication unrelated to Parkinson's disease.

Conclusion. The diagnosis of Parkinson's disease is not an absolute contra-indication to total knee arthroplasty. Our experience suggests that surgeons should assess these patients individually, considering age and the severity of the disease. Total knee replacement, by alleviating pain, correcting flexion deformity and restoring movement, may improve the function of these patients.

Although none of the authors have received or will receive benefits for personal or professional use from a commercial party related directly or indirectly to the subject of this article, benefits have been or will be received but are directed solely to a research fund, foundation, educational institution, or other non-profit institution with which one or more of the authors is associated.

\section{REFERENCES}

Andrews K. Rehabilitation of conditions associated with old age. Int Rehabil Med 1985;7:125-9.

Bartel DL, Burstein AH, Santavicca EA, Insall JN. Performance of the tibial component in total knee replacement: conventional and revision designs. J Bone Joint Surg [Am] 1982;64-A :1026-33.

Diamond SG, Markham CH. Present mortality in Parkinson's disease: the ratio of observed to expected deaths with a method to calculate expected deaths. J Neural Transm 1976;38:259-69.

Gersten JW. Rehabilitation for degenerative diseases of the central nervous system. In: Kottke FJ, Stillwell GK, Lehmann JF, eds. Krusen's handbook of physical medicine and rehabilitation. 3rd ed Philadelphia, etc: WB Saunders Co, 1982:699-706.

Hoehn MM, Yahr MD. Parkinsonism: onset, progression and mortality. Neurology 1967;17:427-42.
Insall JN, Lachiewicz PF, Burstein AH. The posterior stabilized condylar prosthesis: a modification of the total condylar design two to four-year clinical experience. J Bone Joint Surg [Am] 1982;64-A:1317-23.

Insall JN, Hood RW, Flawn LB, Sullivan DJ. The total condylar knee prosthesis in gonarthrosis: a five to nine-year follow-up of the first one hundred consecutive replacements. J Bone Joint Surg [Am] $1983 ; 65-A: 619-28$.

Insall JN. Total knee replacement. In: Insall JN, ed. Surgery of the knee. New York etc: Churchill Livingstone, 1984:587-695.

Kurland LT. Epidemiology: incidence, geographic distribution and genetic considerations. In: Fields WS, ed. Pathogenesis and treatment of Parkinsonism. Sixth Annual Scientific Meeting of the Houston Neurological Society, Texas Medical Center, Houston, Texas. Springfield: Charles C. Thomas, 1958:5-43.

Lapovsky AJ, Slade WR. Movement disorders in the aged. In: Slade WR Jr, ed. Geriatric neurology: selected topics. Mount Kisco, New York: Futura Publishing Co, 1981.

Marttilla RJ, Rinne UK, Siirtola T, Sonninen V. Mortality of patients with Parkinson's disease treated with levodopa. J Neurol 1977:216:147-53.

Nobrega FT, Glattre E, Kurland LT, Okazaki H. Comments on the epidemiology of Parkinsonism including prevalence and incidence statistics for Rochester, Minnesota, 1935-1966. In: Barbeau A, Brunette J-R, eds. Progress in neuro-genetics. Vol. 1. Excerpta Medica International Congress Series No. 175. Amsterdam: Excerpta Medica Foundation, 1967:474-85.

Oni OOA, Mackenney RP. Total knee replacement in patients with Parkinson's disease. J Bone Joint Surg [Br] 1985;67-B:424-5.

Rajput AH. Epidemiology of Parkinson's disease. Can J Neurol Sci 1984;11 (1 Suppl): 156-9.

Selby G. The natural history of Parkinson's disease. Aust Fam Physician 1984;13 (5 Suppl): 1-3.

Steinberg FU. Rehabilitation medicine. In : Steinberg FU, ed. Cowdry's The care of the geriatric patient. 5th ed. Saint Louis, CV Mosby Co, $1976: 403-19$.

Urs WK, Binazzi R, Insall JN, Windsor RE, Padgett D. Custom total knee arthroplasty. American Academy of Orthopaedic Surgeons 55th Annual Meeting, Georgia, February, 1988. American Academy of Orthopaedic Surgeons, 1988:163.

Vince KG, Insall JN, Kelly M, Silva M. Total condylar knee prosthesis: ten to twelve year follow-up and survivorship analysis. Orthop Trans 1987; II:443.

Vince KG, Insall JN, Kelly MA, Silva M. Total knee. American Academy of Orthopaedic Sugeons 55th Annual Meeting, Georgia. February, 1988. American Academy of Orthopaedic Surgeons, 1988:162. 